Revista Brasil. Bot., V.31, n.2, p.323-337, abr.-jun. 2008

\title{
Composição florística da Reserva Municipal de Santa Genebra, Campinas, SP ${ }^{1}$
}

\section{MARIA TEREZA GROMBONE GUARATINI ${ }^{2,5}$, EDUARDO PEREIRA CABRAL GOMES ${ }^{2}$, JORGE YOSHIO TAMASHIRO ${ }^{3}$ e RICARDO RIBEIRO RODRIGUES ${ }^{4}$}

(recebido: 22 de março de 2007; aceito: 21 de maio de 2008)

\begin{abstract}
Floristic compositon of "Reserva Municipal de Santa Genebra", Campinas, SP, Brazil). We carried out a floristic survey of a fragment of a semideciduous forest from May 1996 to April 1998, within one-hectare in the central area of Santa Genebra Reserve (22 49'45" S and 47 06'33" W, 580-610 m a.s.l). We found 201 species in 57 families and 147 genera. The richest families were Fabaceae and Rubiaceae (18 species), Myrtaceae (14 species), Rutaceae (11 species), Solanaceae and Sapindaceae (nine species), Bignoniaceae, Meliaceae and Euphorbiaceae (eight species) and Malvaceae (seven species). About $70 \%$ of the species are late secondary trees and late secondary understory species. Tree species comparison with 25 forests from São Paulo State and northern Paraná State showed that the reserve flora is more similar to forests from Campinas region. Although the forest has disturbed areas there are patch of relatively mature vegetation, thus this area is essential for biodiversity conservation.
\end{abstract}

Key words - floristic, semideciduous forest, successional groups

RESUMO - (Composição florística da Reserva Municipal de Santa Genebra, Campinas, SP). O inventário florístico de um fragmento de floresta semidecídua foi conduzido durante o período de maio de 1996 a abril de 1998 em um hectare de floresta localizado na região central da Reserva de Santa Genebra (2249’45" S e 4706’33" W) a 580-610 m de altitude. Foram identificadas 201 espécies, distribuídas em 57 famílias e 147 gêneros. Fabaceae e Rubiaceae (18 espécies), Myrtaceae (14 spp.), Rutaceae (11 spp.), Solanaceae e Sapindaceae (nove spp.), Bignoniaceae, Meliaceae e Euphorbiaceae (oito spp.), Malvaceae (sete spp.) foram as famílias mais ricas. Cerca de $70 \%$ das espécies foram classificadas como secundárias tardias e secundárias tardias de sub-bosque. A comparação de espécies arbóreas com 25 fragmentos do Estado de São Paulo e Norte do Paraná mostraram que a flora da reserva é mais similar às florestas da região de Campinas. Embora a floresta apresente áreas perturbadas, existem manchas de vegetação relativamente maduras sendo esta área essencial para a conservação da biodiversidade.

Palavras-chave - floresta semidecídua, florística, grupos sucessionais

\section{Introdução}

A floresta estacional semidecidual, que ocupava solos de grande fertilidade no Estado de São Paulo, foi devastada em função da expansão das fronteiras agrícolas (Durigan et al. 2000), restringindo-se atualmente a fragmentos isolados de diferentes formas, tamanhos e graus de preservação. Tais fragmentos representam papel essencial na manutenção da flora local. A caracterização florística e a estrutura fitossociológica dos remanescentes

1. Parte da tese de doutoramento da primeira autora, Programa de PósGraduação em Biologia Vegetal, Universidade Estadual de Campinas, Campinas.

2. Instituto de Botânica, Caixa Postal 3005, 01061-970 São Paulo, SP, Brasil.

3. Universidade Estadual de Campinas, Instituto de Biologia, Departamento de Botânica, Caixa Postal 6109, 13083-970 Campinas, SP, Brasil.

4. Universidade de São Paulo, Escola Superior de Agricultura Luiz de Queiroz, Departamento de Ciências Biológicas, Caixa Postal 9, 13418-900 Piracicaba, SP, Brasil.

5. Autor para correspondência: mgromboneguaratini@gmail.com destas florestas têm sido intensivamente estudadas, disponibilizando informações a respeito do número e distribuição de espécies entre famílias e gêneros (Pagano \& Leitão Filho 1987, César \& Leitão Filho 1990, Salis et al. 1995, Stranghetti \& Ranga 1998, Durigan et al. 2000, Santos \& Kinoshita 2003). Além disso, a relação entre a composição florística de espécies arbóreas e os fatores geográficos, climáticos e edáficos também tem sido investigada (Oliveira-Filho \& Ratter 1995, OliveiraFilho \& Fontes 2000).

A abordagem de que a fragmentação tem impactos sobre a riqueza de espécies (Laurence \& Cochrane 2001, Tabarelli et al. 2004) tem motivado pesquisadores a incorporarem às listagens florísticas a caracterização das espécies arbóreo-arbustivas em grupos sucessionais (Gandolfi et al. 1995, Bernacci \& Leitão Filho 1996, Tabarelli \& Mantovani 1997, Toniato \& Oliveira-Filho 2004). Estas informações são úteis na medida em que fornecem indicações do grau de preservação do ecossistema e são essenciais para o entendimento da dinâmica florestal (Bawa \& McDade 1994). Entretanto, 
a maioria dos levantamentos florísticos foca atenção na vegetação arbóreo-arbustiva, minimizando a importância dos demais hábitos para a caracterização da estrutura da floresta e do nível de complexidade das interações tróficas.

A Reserva Municipal de Santa Genebra é o maior fragmento urbano de floresta estacional semidecidual situado na região de Campinas. Esta floresta, por estar próxima à Universidade Estadual de Campinas, concentra um número grande de trabalhos nas diversas áreas da biologia (Morellato \& Leitão Filho 1996, Pizzo 1997, Fonseca et al. 2004). Apesar disso, nenhum estudo amplo sobre a composição florística foi publicado até o momento. Sabe-se que parques e áreas protegidas são essenciais para a conservação da biodiversidade e que se não forem manejados e preservados adequadamente podem tornar susceptível a extinção de várias espécies (Putz et al. 2001).

Os objetivos deste trabalho foram: 1) apresentar a composição florística de todas as formas de vida fanerogâmica em um trecho contínuo de 1 ha de floresta estacional semidecidual da Reserva Municipal de Santa Genebra; 2) caracterizar as espécies arbustivo-arbóreas ocorrentes na área segundo sua categoria sucessional; 3) comparar a flora arbórea encontrada com a de outros fragmentos florestais.

\section{Material e métodos}

Local de estudo - O estudo foi realizado na Reserva Municipal de Santa Genebra, pertencente à Fundação José Pedro de Oliveira. Esta Reserva, protegida por legislação municipal e estadual, está situada no distrito de Barão Geraldo, região norte do Município de Campinas, SP $\left(22^{\circ} 49^{\prime} 45^{\prime \prime} \mathrm{S}\right.$ e $47^{\circ} 06^{\prime} 33^{\prime \prime} \mathrm{W}$ ) em uma área de 251,8 hectares e altitudes que variam de 580 à $610 \mathrm{~m}$. O clima regional é do tipo Cwa de Koeppen (1948). Segundo o padrão climático definido por Setzer (1966) para o Estado de São Paulo, o clima caracteriza-se como quente úmido, com inverno seco e verão quente e chuvoso, sendo que a temperatura média do mês mais quente encontra-se acima de $22^{\circ} \mathrm{C}$ e a do mês mais frio, abaixo de $18{ }^{\circ} \mathrm{C}$. A formação florestal dominante da Reserva Municipal de Santa Genebra ocorre sobre um relevo suavemente ondulado, sendo que as áreas ocupadas por floresta estacional semidecidual (Veloso et al. 1991) situamse sobre regiões de cotas altimétricas mais elevadas e ocupam 85\% da reserva (Leitão Filho 1995). No interior da floresta são encontradas clareiras, de diferentes idades e tamanhos, originadas tanto da extração seletiva de madeiras nobres, quanto do corte raso para aproveitamento de lenha em alguns trechos restritos (Leitão Filho 1995). A reserva encontra-se inserida em uma matriz agrícola cuja principal atividade é o cultivo de cana-de-açúcar.
Florística - Para o desenvolvimento desse estudo foi escolhido um trecho localizado na região central da Reserva, ocupado por floresta estacional semidecidual. Neste trecho está demarcada uma parcela permanente de $200 \mathrm{~m}$ de comprimento por $50 \mathrm{~m}$ de largura, subdividida em 100 parcelas iguais de $10 \times 10 \mathrm{~m}$, totalizando uma área amostrada de 1 ha (Santos et al. 1996).

As coletas foram realizadas mensalmente, entre maio de 1996 e abril de 1998, mediante caminhadas sistemáticas por toda a área de estudo, considerando-se também a vegetação encontrada nos limites externos da parcela de 1 ha (entorno imediato). Todos os indivíduos presentes no hectare em estádio reprodutivo (presença de flores, frutos ou soros no caso das pteridófitas) tiveram amostras de seu material coletado, prensado, seco e incorporadas ao Herbário da Universidade Estadual de Campinas (UEC). Foram incluídas na listagem florística as espécies arbóreas com PAP $\geq 15 \mathrm{~cm}$ obtidas na amostragem contínua do hectare (Santos et al. 1996) e as espécies ocorrentes no sub-bosque em estádio vegetativo com altura $\geq 0,5 \mathrm{~m}$ e PAP $<15 \mathrm{~cm}$ também desse trecho (1 ha) de floresta.

As espécies amostradas na área foram consideradas arvoretas quando apresentavam ramificações acima de $30 \mathrm{~cm}$ e altura inferior a $4 \mathrm{~m}$; árvores, quando a altura era superior a $4 \mathrm{~m}$; arbustivas, quando lenhosas ou semilenhosas com ramificações originárias do caule até $30 \mathrm{~cm}$ acima do solo; herbáceas, com porte e consistência de erva e caule não lenhoso; epífitas quando se desenvolvem sobre outro vegetal com ausência de dependência nutricional (Rizzini 1997), e lianas, as espécies herbáceas ou lenhosas que usam suporte para sustentação (Müller-Dombois \& Ellenberg 1974).

As fanerógamas foram classificadas dentro de famílias baseadas no sistema APG II (2003) e as pteridófitas segundo Smith et al. (2006). Foram consultados especialistas para identificar alguns materiais e/ou confirmar a identificação. As espécies arbóreas e arbustivas foram enquadradas em classes sucessionais (Budowski 1965) de acordo com as características ecológicas observadas em campo e segundo dados disponíveis de outros autores (Carvalho 1994, Bernacci \& Leitão Filho 1996, Gandolfi et al. 1995, Toniato \& Oliveira-Filho 2004). Neste trabalho, as espécies de estádios finais de sucessão foram denominadas como secundárias tardias e não como climácicas, pois em função da deciduidade, praticamente nenhuma espécie arbórea de florestas semideciduais paulistas apresenta as características descritas para as espécies climácicas encontradas nas florestas pluviais tropicais (Gomes et al. 2003). Arvoretas e arbustos de estádios finais de sucessão, com ocorrência característica sob o dossel da floresta, foram classificados como tolerantes à sombra de sub-bosque.

Similaridade Florística - Foram realizadas comparações florísticas entre as espécies arbóreas encontradas na Reserva de Santa Genebra e outros 25 estudos em florestas mesófilas semideciduais e ripárias do interior do Estado de São Paulo e norte do Paraná (tabela 1, figura 1). As listagens florísticas 
Tabela 1. Características gerais e abreviatura (Abr) dos trabalhos incluídos neste estudo, nome do remanescente, localização geográfica (latitude, longitude) e número de espécies $\left(\mathrm{n}^{\circ} \mathrm{o}\right)$.

Table 1. General characters and abreviations remanescent name, geographical location and species number ( $\mathrm{n}^{\circ}$ ) in each survey including in this paper.

\begin{tabular}{|c|c|c|c|c|}
\hline Levantamento (local, município) & Localização & Referência & Abr & $\mathrm{n}^{\mathrm{o}}$ \\
\hline Campus ESALQ, Piracicaba (SP) & $22^{\circ} 42^{\prime} \mathrm{S}, 47^{\circ} 38^{\prime} \mathrm{W}$ & Rozza \& Ribeiro 1990 & Pira & 45 \\
\hline Estação Ecológica de Assis, Assis (SP) & $22^{\circ} 01^{\prime} \mathrm{S}, 49^{\circ} 55^{\prime} \mathrm{W}$ & Durigan \& Leitão Filho 1995 & EEAs & 55 \\
\hline Estação Ecológica Caetetus, Gália (SP) & $22^{\circ} 24^{\prime} \mathrm{S}, 49^{\circ} 42^{\prime} \mathrm{W}$ & Durigan et al. 2000 & Ctts & 60 \\
\hline $\begin{array}{l}\text { Estação Ecológica de Ibicatu, } \\
\text { Piracicaba (SP) }\end{array}$ & $22^{\circ} 47^{\prime} \mathrm{S}, 47^{\circ} 49^{\prime} \mathrm{W}$ & Costa \& Mantovani 1995 & Ibct & 84 \\
\hline $\begin{array}{l}\text { Estação Ecológica de Paulo de Faria, } \\
\text { Paulo de Faria (SP) }\end{array}$ & $19^{\circ} 56^{\prime} \mathrm{S}, 49^{\circ} 31^{\prime} \mathrm{W}$ & Stranghetti \& Ranga 1998 & $\mathrm{PlFr}$ & 69 \\
\hline $\begin{array}{l}\text { Estação Ecológica de São Carlos, São } \\
\text { Carlos (SP) }\end{array}$ & $22^{\circ} 07^{\prime} \mathrm{S}, 48^{\circ} 04^{\prime} \mathrm{W}$ & Feliciano et al. 2000 & $\mathrm{ESCr}$ & 69 \\
\hline Estação Ecológica de Marília, Marília (SP) & $22^{\circ} 01^{\prime} \mathrm{S}, 49^{\circ} 55^{\prime} \mathrm{W}$ & Durigan \& Leitão Filho 1995 & $\mathrm{EMr}$ & 64 \\
\hline $\begin{array}{l}\text { Estação Ecológica de Sebastião Aleixo da } \\
\text { Silva, Bauru (SP) }\end{array}$ & $22^{\circ} 19^{\prime} \mathrm{S}, 49^{\circ} 04^{\prime} \mathrm{W}$ & Toniato \& Oliveira Filho 2004 & Bru & 103 \\
\hline $\begin{array}{l}\text { Estação Experimental de Mogi Guaçu, } \\
\text { Mogi Guaçu (SP) }\end{array}$ & $22^{\circ} 18^{\prime} \mathrm{S}, 47^{\circ} 13^{\prime} \mathrm{W}$ & Gibbs \& Leitão Filho 1978 & $\mathrm{MjGç}$ & 47 \\
\hline Fazenda Barreiro Rico, Anhembi (SP) & $22^{\circ} 40^{\prime} \mathrm{S}, 48^{\circ} 10^{\prime} \mathrm{W}$ & César \& Leitão-Filho 1990 & Anh & 108 \\
\hline Fazenda Bela Vista, Pedreira (SP) & $22^{\circ} 50^{\prime} \mathrm{S}, 46^{\circ} 55^{\prime} \mathrm{W}$ & Yamamoto et al. 2005 & Pdrr & 131 \\
\hline Fazenda Berrante, Tarumã (SP) & $22^{\circ} 42^{\prime} \mathrm{S}, 50^{\circ} 10^{\prime} \mathrm{W}$ & Durigan \& Leitão Filho 1995 & Brnt & 67 \\
\hline Fazenda Canchin, São Carlos (SP) & $21^{\circ} 57^{\prime} \mathrm{S}, 47^{\circ} 45^{\prime} \mathrm{W}$ & Da Silva \& Soares 2002 & Cnch & 83 \\
\hline Fazenda Santa Irene, Itatinga (SP) & $23^{\circ} 19^{\prime} \mathrm{S}, 48^{\circ} 37^{\prime} \mathrm{W}$ & Ivanauskas et al. 2002 & Ittn & 92 \\
\hline Fazenda São José, Rio Claro (SP) & $22^{\circ} 22^{\prime} \mathrm{S}, 47^{\circ} 28^{\prime} \mathrm{W}$ & $\begin{array}{l}\text { Pagano \& Leitão Filho } 1987, \\
\text { Pagano et al. } 1987\end{array}$ & FSJ & 170 \\
\hline Fazenda São Vicente, Campinas (SP) & $22^{\circ} 53^{\prime} \mathrm{S}, 47^{\circ} 05 \mathrm{~W}$ & Bernacci \& Leitão Filho 1996 & SVcn & 108 \\
\hline Fazenda Tarumã, Tarumã (SP) & $22^{\circ} 49^{\prime} \mathrm{S}, 50^{\circ} 40^{\prime} \mathrm{W}$ & Durigan \& Leitão Filho 1995 & Trmã & 63 \\
\hline $\begin{array}{l}\text { Gleba Capetinga Oeste, Parque Estadual } \\
\text { de Vassununga, Santa Rita do Passa } \\
\text { Quatro (SP) }\end{array}$ & $21^{\circ} 43^{\prime} \mathrm{S}, 47^{\circ} 35^{\prime} \mathrm{W}$ & Martins 1991 & Vas1 & 84 \\
\hline $\begin{array}{l}\text { Gleba Praxedes P. E. de Vassununga, } \\
\text { Santa Rita do Passa Quatro (SP) }\end{array}$ & $21^{\circ} 50^{\prime} \mathrm{S}, 47^{\circ} 37^{\prime} \mathrm{W}$ & Bertoni et al. 1988 & Vas2 & 59 \\
\hline $\begin{array}{l}\text { Gleba Capetinga P. E. de Vassununga, } \\
\text { Santa Rita do Passa Quatro (SP) }\end{array}$ & $21^{\circ} 41^{\prime} \mathrm{S}, 47^{\circ} 37^{\prime} \mathrm{W}$ & Vieira et al. 1989 & Vas3 & 56 \\
\hline Mata do Rio Cachoeira, Itirapina (SP) & $22^{\circ} 23^{\prime} \mathrm{S}, 47^{\circ} 53^{\prime} \mathrm{W}$ & $\begin{array}{l}\text { Kotchetkoff-Henriques \& } \\
\text { Joly } 1994\end{array}$ & Itira & 74 \\
\hline $\begin{array}{l}\text { Mata do Ribeirão Cachoeira, } \\
\text { Campinas (SP) }\end{array}$ & $22^{\circ} 47^{\prime} \mathrm{S}, 46^{\circ} 52^{\prime} \mathrm{W}$ & Santos \& Kinoshita 2003 & $\mathrm{RCch}$ & 175 \\
\hline $\begin{array}{l}\text { Parque Estadual Mata dos Godoy, } \\
\text { Londrina (PR) }\end{array}$ & $23^{\circ} 27^{\prime} \mathrm{S}, 51^{\circ} 15^{\prime} \mathrm{W}$ & Soares-Silva \& Barroso 1992 & God & 91 \\
\hline $\begin{array}{l}\text { Parque Estadual do Morro do Diabo, } \\
\text { Teodoro Sampaio (SP) }\end{array}$ & $22^{\circ} 30^{\prime} \mathrm{S}, 52^{\circ} 20^{\prime} \mathrm{W}$ & Baitello et al. 1988 & $\mathrm{MDb}$ & 110 \\
\hline Reserva Estadual de Bauru, Bauru (SP) & $22^{\circ} 19^{\prime} \mathrm{S}, 49^{\circ} 04^{\prime} \mathrm{W}$ & Cavassan et al. 1984 & $\mathrm{Bau}$ & 56 \\
\hline $\begin{array}{l}\text { Reserva Municipal de Santa Genebra, } \\
\text { Campinas (SP) }\end{array}$ & $22^{\circ} 49^{\prime} \mathrm{S}, 47^{\circ} 06^{\prime} \mathrm{W}$ & Este trabalho & SGnb & 120 \\
\hline
\end{tabular}




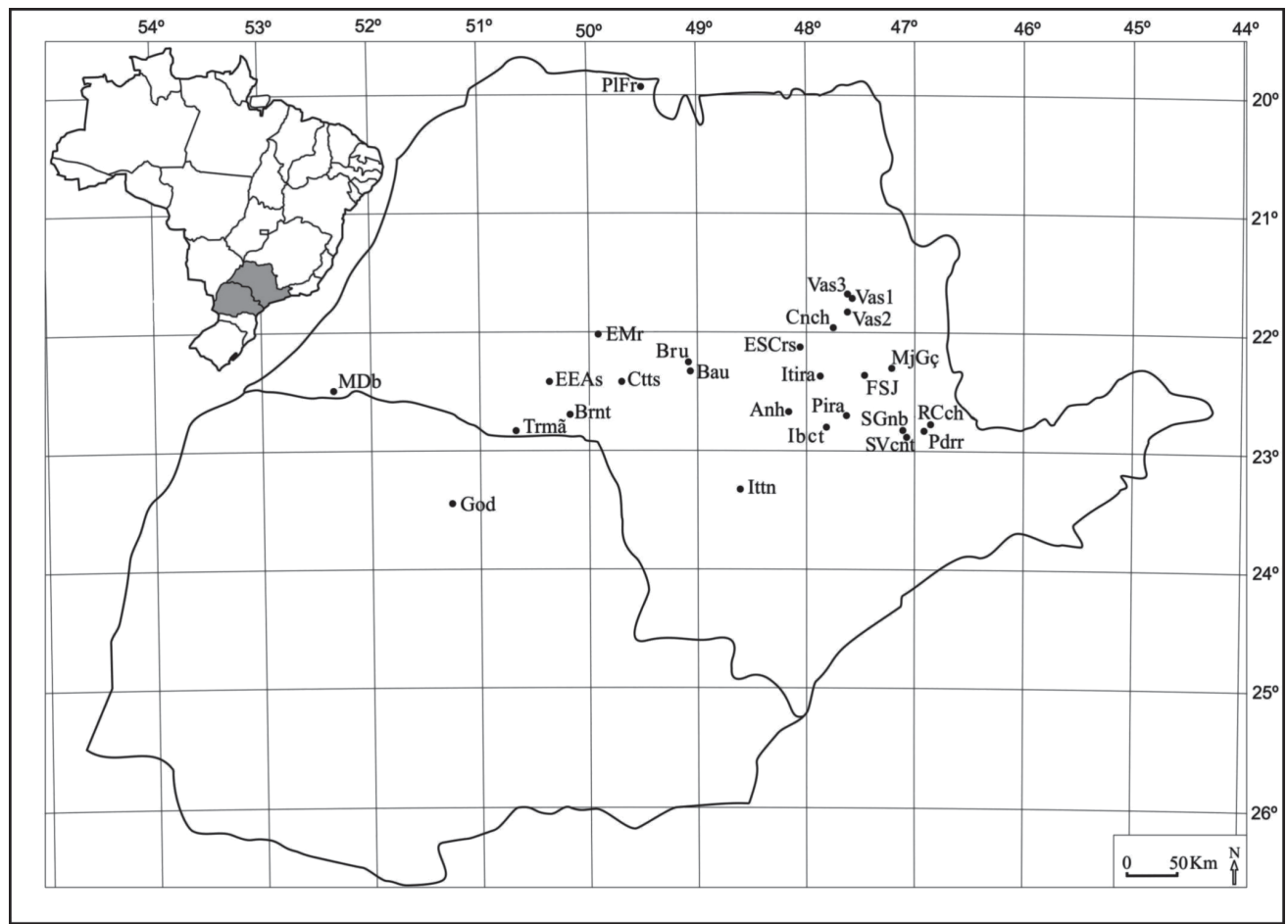

Figura 1. Localização geográfica das 26 áreas de floresta localizadas nos Estados de São Paulo e Paraná utilizadas nas análises florísticas. Veja a tabela 1 para abreviaturas de áreas.

Figure 1. Geographic location of the 26 forests areas in São Paulo and Paraná State compared for the floristic analyzes. Study sites abbreviations in table 1.

foram sinonimizadas segundo revisões taxonômicas recentes. O número total de espécies difere dos encontrados nos trabalhos originais, uma vez que só foram incluídos os indivíduos identificados até espécie, foram excluídas espécies exóticas e algumas espécies foram reunidas após revisões taxonômicas. A partir da matriz de presença/ausência de espécies arbóreas foi calculado o índice de similaridade de Sørensen e gerada a matriz de similaridade a partir da qual o agrupamento foi feito por média aritmética de grupo não ponderada (UPGMA). Os dados foram tratados com auxílio do programa MVSP 3.12 (Kovach 1999).

\section{Resultados e discussão}

Florística da área - Foram identificadas 201 espécies, distribuídas em 57 famílias e 147 gêneros (tabela 2). As árvores representaram o hábito mais abundante (53,7\% correspondentes a 108 espécies), seguida das lianas (17,4\% correspondentes a 35 espécies), arbustos (14,4\% correspondentes a 29 espécies), ervas (8,0\% correspondentes a 16 espécies), arvoretas (6,0\% e 12 espécies) e epífitas ( $0,5 \%$ correspondente a uma espécie). Coffea arabica foi a única espécie exótica presente na área de estudo $(0,5 \%)$.
Considerando-se exclusivamente a flora arbustivoarbórea, as famílias mais ricas foram Fabaceae e Rubiaceae (18 spp.), Myrtaceae (14 spp.), Rutaceae (11 spp.), Solanaceae e Sapindaceae (nove spp.), Bignoniaceae, Meliaceae e Euphorbiaceae (oito spp.), Malvaceae (sete spp.), Lauraceae e Salicaceae (quatro spp.). Tais famílias agrupadas totalizaram 105 espécies, correspondendo a $75 \%$ das espécies arbustivo-arbóreas, e estão entre as que apresentaram um número maior de espécies em remanescentes na região de Campinas (Bernacci \& Leitão Filho 1996, Santos \& Kinoshita 2003, Yamamoto et al. 2005) e florestas mesófilas semideciduais baixo montanas (Oliveira-Filho \& Fontes 2000). A presença das famílias Malvaceae e Salicaceae, não mencionadas nos trabalhos acima citados, se deve ao sistema de classificação adotado neste trabalho (APG II). A família Malvaceae passou a incluir espécies comuns nas florestas do interior de São Paulo que anteriormente eram classificadas nas famílias Bombacaceae (Ceiba speciosa e Pseudobombax grandiflorum e Tiliaceae (Luehea divaricata e Luehea speciosa). O mesmo ocorre com a família Salicaceae, que passou a incluir espécies do gênero Casearia, comuns em florestas semideciduais, 
Tabela 2. Espécies da Reserva Municipal de Santa Genebra, Campinas, SP. Hábito (av = árvore; at = arvoreta; arb = arbusto; herb = herbácea; $\mathrm{ep}=$ epífita; lin = liana), grupo ecológico $(\mathrm{p}=$ pioneiras, $\mathrm{si}=$ secundária inicial, $\mathrm{st}=$ secundária tardia, $\mathrm{st} / \mathrm{sb}=$ tolerante a sombra de sub-bosque) e número de coletor do material coletado por M.T.G. Guaratini incluído no Herbário da Universidade Estadual de Campinas (UEC)

Table 2. Species of the "Reserva Municipal de Santa Genebra", municipality of Campinas, São Paulo State. Habit (av = tree; at $=$ treelet; $\operatorname{arb}=$ shrub; ep = epiphytic; lin = vines), ecological group ( $\mathrm{p}=$ pioneer; $\mathrm{si}$ = early secondary, $\mathrm{st}=$ late secondary, $\mathrm{st} / \mathrm{sb}=$ understory late secondary) and voucher number of M.T.G. Guaratini included in the Universidade Estadual de Campinas Herbarium (UEC).

Família/Espécie

Hábito

Grupo ecológico

Material testemunho

1. ACANTHACEAE

Mendoncia puberula (Mart.) Nees

Ruellia brevifolia (Pohl) C. Ezcurra

Chamissoa altissima (Jacq.) Kunth

Hebanthe paniculata Mart.

3. ANACARDIACEAE

Astronium graveolens Jacq.

4. ANNONACEAE

Duguetia lanceolata A. St.-Hil.

Guatteria nigrescens Mart.

Rollinia sylvatica (A. St.-Hil.) Mart.

Xylopia brasiliensis Spreng.

5. APOCYNACEAE

Aspidosperma cylindrocarpon Müll. Arg.

Aspidosperma polyneuron Müll. Arg.

Gonolobus rostratus (Vahl) Schult.

Forsteronia pubescens A. DC.

Prestonia coalita (Vell.) Woodson

Prestonia tomentosa Seem.

6. ARECACEAE

Syagrus romanzoffiana (Cham.) Glassman

7. ASTERACEAE

Ageratum conyzoides L.

Erechtites valerianifolius (Link ex Spreng.) DC.

Chromolaena maximilianii (Schrad.) R. M. King \&

H. Rob.

Vernonia diffusa Less.

Vernonia discolor (Spreng.) Less.

8. BIGNONIACEAE

Adenocalymma marginatum (Cham.) DC.

Anemopaegma chamberlaynii (Sims) Bureau \& K.Schum.

Jacaranda micrantha Cham.

Lundia obliqua Sond.

Mansoa difficilis (Cham.) Bureau \& K. Schum.

Pithecoctenium crucigerum (L.) A. H. Gentry

Pyrostegia venusta (Ker Gawl.) Miers

Zeyheria tuberculosa (Vell.) Bureau lin

arb

$\operatorname{lin}$

$41 ; 101 ; 143 ; 180 ; 356$

$\mathrm{st} / \mathrm{sb} \quad 173$

$06 ; 20 ; 38 ; 76$

27; 40; 51; 59; 330; 394

arv

st

$65 ; 1376$

arv

arv

arv

arv

arv

$\operatorname{arv}$

lin

lin

lin

lin

$\begin{array}{ll}\text { st } & \text { s/n } \\ \text { st } & 176 ; 233 \\ \text { si } & \text { s/n } \\ \text { st } & \text { s/n }\end{array}$

$\operatorname{arv}$

si

UEC 114298

UEC 47248

364

177

269

137

herb

herb

herb

299

arv

arv

$\mathrm{p}$

UEC 128584

$\mathrm{s} / \mathrm{n}$

lin

lin

arv

lin

lin

lin

lin

arv
4; 362

$\mathrm{s} / \mathrm{n}$

$\mathrm{s} / \mathrm{n}$

268

130; 335

357

108

si UEC 47268

continua 
continuação

Família/Espécie

Hábito

Grupo ecológico

Material testemunho

9. BORAGINACEAE

Cordia ecalyculata Vell.

Cordia trichotoma (Vell.) Arrab. ex Steud.

Heliotropium sp.

Patagonula americana $\mathrm{L}$.

$\operatorname{arv}$

arv

herb

arv

arv

Protium spruceanum (Benth.) Engl.

11. CACTACEAE

Pereskia aculeata Mill.

Rhipsalis sp.

12. CANNABACEAE

Celtis iguanea (Jacq.) Sarg.

Trema micrantha (L.) Blume

13. CELASTRACEAE

Hippocratea volubilis $\mathrm{L}$.

Maytenus aquifolium Chodat

Maytenus robusta Reissek

14. CHRYSOBALANACEAE

Hirtella hebeclada Moric. ex DC.

15. COMMELINACEAE

Dichorisandra sp.

16. CUCURBITACEAE

Wilbrandia verticillata Cogn.

17. EUPHORBIACEAE

Actinostemon klotzschii (Didr.) Pax

Croton floribundus Spreng.

Croton priscus Croizat

Dalechampia pentaphylla Lam.

Dalechampia triphylla Lam.

Pachystroma longifolium (Ness) I. M. Johnston

Sebastiania edwalliana Pax \& K. Hoffm

Tragia sellowiana (Baill.) Müll. Arg.

18. FABACEAE

Acacia polyphylla DC.

Canavalia parviflora Benth.

Centrolobium tomentosum Guill. ex Benth

Copaifera langsdorffii Desf.

Holocalyx balansae Micheli

Inga subnuda Benth. subsp. luschnatiana (Benth.)

T. D. Penn.

Inga marginata Willd.

Inga vera Willd. ssp. affinis (DC.) T. D. Penn.

Machaerium brasiliense Vogel

Machaerium hirtum (Vell.)

Machaerium stipitatum (DC.) Vogel

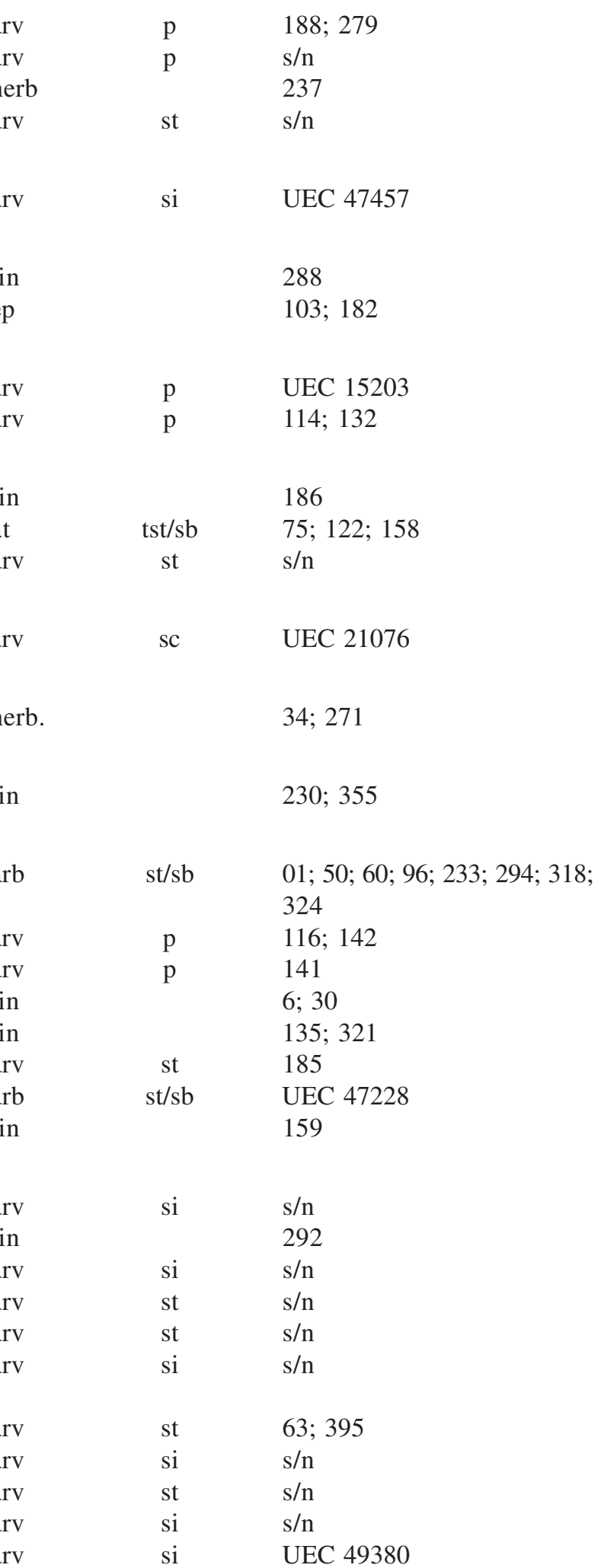

continua 
continuação

Família/Espécie

Hábito

Grupo ecológico

Material testemunho

18. FABACEAE

Machaerium vestitum Vogel

Machaerium villosum Vogel

Myroxylon peruiferum L. f.

Piptadenia gonoacantha (Mart.) J. F. Macbr.

Rhynchosia phaseoloides (Sw.) DC.

Senna macranthera (DC. ex Collad.) H. S. Irwin \& Barneby

Sweetia fruticosa Spreng.

$\operatorname{arv}$

arv

arv

arv

lin

arv

arv

19. LACISTEMACEAE

Lacistema hasslerianum Chodat

20. LAURACEAE

Cryptocarya moschata Ness \& Mart.

Nectandra megapotamica (Spreng.) $\mathrm{Mez}$

Ocotea beulahiae Baitello

Ocotea puberula (Rich.) Ness

21. LAMIACEAE

Aegiphila sellowiana Cham.

22. LECYTHIDACEAE

Cariniana estrellensis (Raddi) Kuntze

Cariniana legalis (Mart.) Kuntze

23. LYTHRACEAE

Lafoensia pacari A. St.-Hil.

24. MALPIGHIACEAE

Dicella bracteosa (A. Juss.) Griseb.

Heteropterys aceroides Griseb.

25. MALVACEAE

Abutilon peltatum K. Schum.

Ceiba speciosa (A. St.-Hil.) Ravenna

Luehea divaricata Mart.

Luehea speciosa Willd.

Pseudobombax grandiflorum (Cav.) A. Robyns

Triumfetta semitriloba L. ex A. Rich

Wissadula hernandioides (L'Hér.) Garcke

26. MELASTOMATACEAE

Miconia discolor DC.

Miconia pusilliflora (DC.) Naudin

27. MELIACEAE

Cabralea canjerana (Vell.) Mart.

Cedrela fissilis Vell.

Guarea guidonia (L.) Sleumer

Trichilia catigua A. Juss.

Trichilia claussenii C. DC.

Trichilia elegans A. Juss.

Trichilia hirta L.

Trichilia pallida Sw.

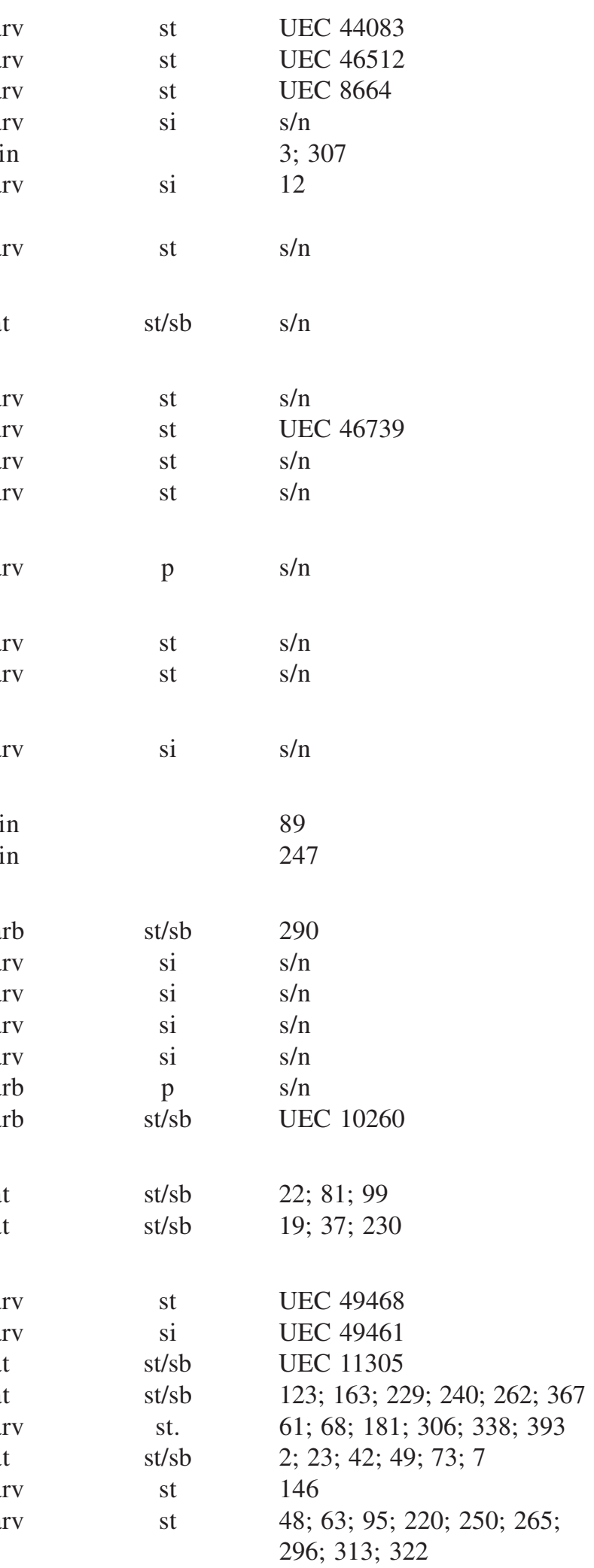

continua 
continuação

Família/Espécie

Hábito

Grupo ecológico

Material testemunho

28. MONIMIACEAE

Mollinedia widgrenii A. DC.

at

$\mathrm{st} / \mathrm{sb}$

47; 118

29. MORACEAE

Maclura tinctoria (L.) D. Don ex Steud

Sorocea bonplandii (Baill.) W. C. Burger, Lanj. \& Wess. Boer.

30. MYRSINACEAE

Myrsine umbellata Mart.

$\begin{array}{lll}\operatorname{arv} & \mathrm{si} & \mathrm{s} / \mathrm{n} \\ \operatorname{arv} & \mathrm{sc} & \mathrm{s} / \mathrm{n}\end{array}$

31. MYRTACEAE

Calyptranthes concinna DC.

Campomanesia maschalantha (O. Berg.) Kiaersk.

Campomanesia guaviroba (DC.) Kiaersk.

Eugenia excelsa O. Berg

Eugenia florida DC.

Eugenia ligustrina Cambess.

Eugenia uniflora L.

Eugenia sp. 1

Eugenia sp. 2

Gomidesia affinis (Cambess.) D. Legrand

Myrceugenia campestris (DC.) D. Legrand \& Kausel

Myrciaria floribunda (H. West ex Willd.) O. Berg

Myrcia rostrata DC.

Syphoneugenia densiflora O. Berg

\begin{tabular}{|c|c|c|}
\hline $\operatorname{arv}$ & si & $\mathrm{s} / \mathrm{n}$ \\
\hline $\operatorname{arv}$ & st & $164 ; 388$ \\
\hline arv & st & $\mathrm{s} / \mathrm{n}$ \\
\hline $\operatorname{arv}$ & st & $\mathrm{s} / \mathrm{n}$ \\
\hline arv & st & $106 ; 164$ \\
\hline arb & $\mathrm{st} / \mathrm{sb}$ & 86 \\
\hline $\operatorname{arv}$ & st & $\mathrm{s} / \mathrm{n}$ \\
\hline $\operatorname{arv}$ & st & $\mathrm{s} / \mathrm{n}$ \\
\hline arv & sc & $\mathrm{s} / \mathrm{n}$ \\
\hline $\operatorname{arv}$ & $\mathrm{sc}$ & $\mathrm{s} / \mathrm{n}$ \\
\hline $\operatorname{arv}$ & st & $\mathrm{s} / \mathrm{n}$ \\
\hline arb & $\mathrm{st} / \mathrm{sb}$ & $\mathrm{s} / \mathrm{n}$ \\
\hline $\operatorname{arv}$ & $\mathrm{st} / \mathrm{sb}$ & $153 ; 184 ; 317$ \\
\hline arv & st & $121 ; 148 ; 175 ; 179 ; 232$ \\
\hline $\operatorname{arv}$ & st & $\mathrm{s} / \mathrm{n}$ \\
\hline $\operatorname{arv}$ & st & $\mathrm{s} / \mathrm{n}$ \\
\hline $\operatorname{arv}$ & st & $54 ; 313$ \\
\hline $\operatorname{arv}$ & st & $\mathrm{s} / \mathrm{n}$ \\
\hline herb & & 259 \\
\hline herb & & 383 \\
\hline arb & $\mathrm{st} / \mathrm{sb}$ & $93 ; 115 ; 134 ; 166$ \\
\hline arb & $\mathrm{st} / \mathrm{sb}$ & $102 ; 109 ; 172 ; 323 ; 396$ \\
\hline arb & $\mathrm{st} / \mathrm{sb}$ & $33 ; 58 ; 359$ \\
\hline $\operatorname{arv}$ & $\mathrm{sc}$ & $\mathrm{s} / \mathrm{n}$ \\
\hline arv & st & $\mathrm{s} / \mathrm{n}$ \\
\hline arv & st & 270 \\
\hline at & $\mathrm{st} / \mathrm{sb}$ & 112 \\
\hline herb & & $291 ; 293$ \\
\hline herb & & $279 ; 336$ \\
\hline $\mathrm{rb}$ & & $235 ; 319 ; 375$ \\
\hline
\end{tabular}

continua

Guapira opposita (Vell.) Reitz

Pisonia ambigua Heimerl

33. OPILIACEAE

Agonandra excelsa Griseb.

34. ORCHIDACEAE

Mesadenella cuspidata (Lindl.) Garay

Catasetum sp.

35. PIPERACEAE

Piper amalago $\mathrm{L}$.

Piper baptisianum C. DC.

Piper crassinervium Kunth

36. PHYLLANTHACEAE

Phyllanthus acuminatus Vahl

Savia dictyocarpa Müll. Arg.

37. PHYTOLACCACEAE

Seguieria americana L.

38. PICRAMNIACEAE

Picramnia warmingiana Engl.

39. POACEAE

Lasiacis ligulata Hitchc. \& Chase

Panicum aff. maximum Jacq.

Pharus sp.
$279 ; 336$

$235 ; 319 ; 375$ 
continuação

Família/Espécie

Hábito

Grupo ecológico

Material testemunho

40. POLYGALACEAE

Polygala klotzschii Chodat

arb

$\mathrm{st} / \mathrm{sb}$

$84 ; 152$

41. POLYPODIACEAE

Microgramma lindbergii (Mett.) Sota

herb

42. PTERIDACEAE

Doryopteris pentagona. Pic. Serm.

Pteris denticulata Sw.

herb

257

herb

174

43. RANUNCULACEAE

Clematis dioica $\mathrm{L}$.

lin

$\mathrm{s} / \mathrm{n}$

44. RHAMNACEAE

Colubrina glandulosa Perk.

Gouania virgata Reissek

Rhamnidium elaeocarpum Reissek

arv

$\operatorname{lin}$

st

$\mathrm{s} / \mathrm{n}$

arv

st

$\mathrm{s} / \mathrm{n}$

45. RUBIACEAE

Amaioua intermedia Mart.

Chiococca alba (L.) Hitch.

Chomelia obtusa Cham. \& Schltdl.

Chomelia sericea Müll. Arg.

Coffea arabica $\mathrm{L}$.

Coussarea contracta (Walp.) Müll. Arg.

Coutarea hexandra K. Schum.

Ixora gardneriana Benth.

Ixora venulosa Benth.

Mapourea sessiliflora Müll. Arg.

arv

lin

arb

arb

arb

arv

arv

arv

arv

arb

Psychotria appendiculata Müll. Arg.

Psychotria carthagenensis Jacq.

arb

arb

Psychotria cephalantha (Müll. Arg.) Standl.

Psychotria leiocarpa Cham. \& Schldtl.

Psychotria myriantha Müll. Arg.

Psychotria niveobarbata Müll. Arg.

Psychotria vauthieri Müll. Arg.

Rudgea jasminoides Müll. Arg.

arb

arb

arb

arb

arv

at

$\mathrm{st} / \mathrm{sb}$

$\mathrm{s} / \mathrm{n}$

$\mathrm{st} / \mathrm{sb} \quad \mathrm{s} / \mathrm{n}$

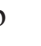

$\mathrm{st} / \mathrm{sb} \quad \mathrm{s} / \mathrm{n}$

$\mathrm{st} / \mathrm{sb} \quad \mathrm{s} / \mathrm{n}$

exótica $\quad \mathrm{s} / \mathrm{n}$

st $\quad \mathrm{s} / \mathrm{n}$

st UEC 31080

st $129 ; 165 ; 194 ; 236$

st $\quad 80 ; 111 ; 131 ; 241 ; 274 ; 330$

st/sb $\quad 170 ; 234 ; 256 ; 275 ; 341 ;$

$354 ; 391$

$\mathrm{st} / \mathrm{sb} \quad 266 ; 371$

6. RUTACEAE

Almeidea lilacina A. St.-Hil.

Balfourodendron riedelianum (Engl.) Engl.

Conchocarpus pentandrus (A. St.-Hil.) Kallunki \& Pirani

Esenbeckia leiocarpa Engl.

Esenbeckia febrifuga (A. St.-Hil.) Juss.

Galipea jasminiflora (A. St.-Hil.) Engl.

Metrodorea nigra A. St.-Hil.

Zanthoxyllum acuminatum (Sw.) Sw.

Zanthoxyllum fagara (L.) Sarg.

Zanthoxyllum monogynum A. St.-Hil.

Zanthoxyllum rhoifolium Lam.

$\begin{array}{lcl}\text { arv } & \text { si } & 126 ; 390 \\ \text { arv } & \text { st } & \text { s/n } \\ \text { arv } & \text { st/sb } & \text { s/n } \\ \text { arv } & \text { st } & 70 ; 133 ; 1111 \\ \text { arv } & \text { st/sb } & 16 \\ \text { at } & \text { st/sb } & 167 ; 227 ; 228 ; \\ \text { arv } & \text { st } & 144 \\ \text { arv } & \text { st } & 150 ; 161 ; 183 \\ \text { arv } & \text { si } & \text { s/n } \\ \text { arv } & \text { st } & 368 \\ \text { arv } & \text { p } & \mathrm{s} / \mathrm{n}\end{array}$


continuação

Família/Espécie

Hábito

Grupo ecológico

Material testemunho

47. SALICACEAE

Casearia decandra Jacq.

Casearia gossypiosperma Briq.

Casearia obliqua Spreng.

Casearia sylvestris $\mathrm{Sw}$.

$\begin{array}{ccl}\operatorname{arv} & \text { st } & \text { UEC } 47226 \\ \operatorname{arv} & \text { st/sb } & \text { s/n } \\ \operatorname{arv} & \text { st } & \text { s/n } \\ \text { arv } & \text { si } & \text { UEC } 49686\end{array}$

48. SAPINDACEAE

Allophylus edulis (A. St.-Hil., Cambess. \& Juss.) Radlk.

arv

Cupania vernalis Cambess.

Diatenopteryx sorbifolia Radlk.

Matayba elaeagnoides Radlk.

Serjania caracasana (Jacq.) Willd.

Serjania communis Cambess.

Serjania grandiflora Cambess.

Serjania sp. 1

Urvillea ulmacea Kunth

arv

arv

arv

$\operatorname{lin}$

$\operatorname{lin}$

lin

lin

lin

$\mathrm{p} \quad 74$

\section{SAPOTACEAE}

Chrysophyllum gonocarpum (Mart. \& Eichl.) Engl.

$\operatorname{arv}$

50. SOLANACEAE

Cestrum sendtnerianum Mart. ex Sendtn.

Solanum acerifolium Dunal

Solanum alternatopinnatum Steud.

Solanum americanum Mill.

Solanum argenteum Dunal

Solanum gnaphalocarpon Vell.

Solanum granuloso-leprosum Dunal

Solanum hirtellum (Spreng.) Hassl.

Solanum swartzianum Roem. \& Schult.

51. THEACEAE

Gordonia fruticosa (Schrad.) H. Keng

52. TRIGONIACEAE

Trigonia nivea Cambess.

si $\mathrm{s} / \mathrm{n}$

st $\quad \mathrm{s} / \mathrm{n}$

si

UEC 56653

$39 ; 55 ; 57 ; 311 ; 314$

$15 ; 18 ; 26 ; 45$

$\mathrm{S} / \mathrm{n}$

272

$5 ; 31 ; 79$

st

85

arb

herb

$\mathrm{st} / \mathrm{sb}$

arb

$\mathrm{st} / \mathrm{sb}$

$88 ; 283$

$\mathrm{st} / \mathrm{sb}$

325

herb

$\mathrm{st} / \mathrm{sb}$

56

at

arb

$\mathrm{p}$

$\mathrm{s} / \mathrm{n}$

$\mathrm{st} / \mathrm{sb}$

92; 103; 157; 243

arb

arb

arv

$\mathrm{p}$

$170 ; 365$

$298 ; 315$

p $\quad 174 ; 261 ; 382 ; 366$

$\mathrm{p}$

$\mathrm{s} / \mathrm{n}$

arv

st

$\mathrm{s} / \mathrm{n}$

53. URTICACEAE

Cecropia pachystachya Trécul

Pilea sp.

Urera baccifera (L.) Gaudich.

arv

herb

p s/n

arb

$\mathrm{p}$

253

54. VERBENACEAE

Lantana brasiliensis Link.

lin

Petrea volubilis L.

lin

$32 ; 196$

55. VIOLACEAE

Hybanthus atropurpureus (A. St.-Hil.) Taub.

arb

$\mathrm{st} / \mathrm{sb}$

$\mathrm{s} / \mathrm{n}$

56. VITACEAE

Cissus sulcicaulis (Baker) Planch.

$\operatorname{lin}$

$28 ; 212$

VOCHYSIACEAE

Qualea jundiahy Warm.

arv

st

$\mathrm{s} / \mathrm{n}$ 
anteriormente classificadas em Flacourtiaceae (Cronquist 1981). Os gêneros arbustivos e arbóreos com maior número de espécies na Floresta de Santa Genebra foram: Psychotria com sete, Solanum e Eugenia com seis, Trichilia e Machaerium com cinco, Zanthoxylum com quatro. Estes seis gêneros, além de Ficus, são os que apresentaram um maior número de espécies no levantamento realizado por Santos \& Kinoshita (2003) na região de Campinas.

Entre as lianas, o terceiro hábito mais abundante, as famílias mais ricas foram Bignoniaceae, com seis espécies, Sapindaceae com cinco espécies, Apocynaceae com três espécies e Malpighiaceae com duas espécies. Estas famílias estão entre as mais importantes encontradas em fragmentos florestais (Hora \& Soares 2002). Em florestas tropicais a riqueza e abundância de lianas estão correlacionadas negativamente com a precipitação total e positivamente com a sazonalidade (Schinitzer 2005). Segundo o autor, as lianas apresentam maior tolerância ao estresse hídrico em relação às arbóreas, arbustivas, herbáceas e epífitas, apresentando um crescimento relativamente maior na estação seca e ocupando preferencialmente, tanto em abundância total como em biomassa, a borda das florestas onde seu crescimento é favorecido pelo aumento de radiação. Tais aspectos, provavelmente, justificam a ampla ocorrência na Reserva de Santa Genebra, uma floresta sazonal e relativamente perturbada, principalmente nas áreas de borda e onde houve ocorrência de fogo. Nestas áreas, a presença de lianas mais agressivas pode alterar a dinâmica florestal retardando o processo de regeneração natural.

No interior da floresta foram encontradas espécies herbáceas e arbustivas caracterizadas como invasoras de culturas agrícolas, como Ageratum conyzoides, Erechtites valerianifolius, Chromolaena maximilianii, Lasiacis ligulata, Panicum aff. maximum e Solanum americanum. Tais espécies não são componentes da vegetação florestal, sendo, porém, de ocorrência freqüente, na borda de florestas submetidas a alterações naturais ou antrópicas (Bernacci \& Leitão Filho 1996), como, por exemplo, a utilização de áreas florestais para descarga de água superficial dos sistemas agrícolas, muito comum em remanescentes circundados por áreas de agricultura. Além disso, os eficientes mecanismos de dispersão dos propágulos das espécies invasoras associados à presença de mecanismos de dormência de suas sementes (Baker 1974) proporcionam um acesso fácil dessas espécies ao interior da floresta mediante sua incorporação e permanência no banco de sementes do solo (Graham \& Hopkins 1990, Hopkins et al. 1990). Estas espécies, mediante o surgimento de condições propícias para a germinação, como por exemplo, a abertura de clareiras, parte essencial da dinâmica florestal (Brokaw 1985), passariam a coexistir com a vegetação florestal.

A flora da Reserva Municipal de Santa Genebra apresentou várias espécies não citadas para as florestas estacionais semideciduais do Estado de São Paulo, dentre elas Agonandra excelsa, Coussarea contracta, Myrceugenia campestris, Piper baptisianum, Phyllanthus acuminatus, Psychotria myriantha, P. niveobarbata, Seguieria floribunda, Solanum alternatopinnatum, $S$. gnaphalocarpon. Fatores como a origem, a intensidade do distúrbio, e o tamanho e grau de preservação do fragmento podem favorecer ou não a perpetuação de espécies em determinadas áreas.

Dentre as arbustivo-arbóreas, 19 espécies $(12,7 \%)$ foram classificadas como pioneiras, 25 (16,8\%) como secundárias iniciais, 58 (38,9\%) como secundárias tardias, 43 (28,9\%) como secundárias tardias pertencentes ao sub-bosque e quatro $(2,7 \%)$ permaneceram sem identificação. A floresta da Reserva apresenta-se como um mosaico de fases sucessionais distintas, onde áreas ocupadas por espécies de estádios finais de sucessão (cerca de 70\%), são adjacentes a outras muito perturbadas, ocupadas por espécies de estádios iniciais de sucessão, bambus e espécies de plantas daninhas.

A riqueza de espécies de estádios intermediários de sucessão tem sido descrita como uma particularidade das florestas estacionais semideciduais do Estado de São Paulo, fundamentada na deciduidade sazonal de algumas espécies do dossel da floresta e no histórico de perturbação antrópica das áreas. Tanto os distúrbios de origem natural quanto antrópica (a retirada seletiva de espécies arbóreas) ocasionam a formação de pequenas clareiras, que podem ser colonizadas predominantemente por espécies não pioneiras (Brokaw \& Scheiner 1989, Whitmore 1989) proporcionando a manutenção de um número maior de espécies desse grupo no interior da floresta. A riqueza e a importância de espécies de estádio intermediário em contraposição ao número reduzido de espécies pioneiras encontradas colonizando pequenas clareiras na Mata Atlântica (Tabarelli \& Mantovani 1997) podem acrescentar evidências a esta hipótese. Embora a dependência de grandes clareiras das espécies intolerantes à sombra tenha sido demonstrada, não existem evidências claras a respeito da importância das clareiras para a maioria das espécies tolerantes à sombra (Denslow \& Hartshorn 1994). Não existem estudos que avaliem a importância das clareiras sazonais no recrutamento e desenvolvimento das espécies.de florestas estacionais semideciduais.

Similaridade florística - Há um padrão de mudança gradual de sudeste a noroeste com tendência a formação 
de grupos em escala local, para 12 dos 26 levantamentos, e de encadeamento em escala geral, tendência à ligação com grupos já formados em detrimento a formação de novos grupos. Das 720 espécies registradas para os 26 locais na matriz, $336(46,7 \%)$ ocorreram somente em um local, e apenas $186(25,8 \%)$ em mais de três locais. Por haver poucas espécies comuns entre os levantamentos, os índices de similaridade situaram-se abaixo de 0,50, com exceção dos três primeiros grupos formados.

De maneira geral, os fragmentos mais isolados no dendrograma, com menor similaridade, incluem áreas com características peculiares como Assis (EEAs) que é uma mata ciliar muito próxima ao cerrado e que se distingue das demais por apresentar três espécies de Symplocaceae; Mogi Guaçu (MjGç) e a Floresta em Itatinga (Ittn), respectivamente uma floresta ripária e uma mata de brejo, e áreas perturbadas como em Piracicaba (Pira) que é um fragmento pequeno ( 9 ha), a Fazenda São Vicente (SVcn) e a Floresta em Bauru (Bau). A flora arbórea da Estação Ecológica de Paulo de Faria $(\mathrm{PlFr})$ apresentou características intermediárias às acima descritas e é a mais isolada geograficamente. Entre as demais áreas, locais próximos tenderam a se agrupar, por exemplo, os três levantamentos no P. E. de Vassununga (Vas1, Vas2 e Vas3) e as matas no oeste paulista (Fazendas Berrante (Brnt), Fazenda Tarumã (Trmã), E. E. Marília
(EMr) e P. E. Caetetus (Ctts)) que por sua vez se agruparam com outros locais e/ou grupos menores sem uma clara correlação com a distância geográfica.

O índice de correlação cofenética (CC) que mede o quanto o dendrograma representa os dados originais foi de 0,88 , bem acima do mínimo de 0,75 , considerado para uma boa representação (McGarigal et al. 2000).

No processo de análise dos dados foi obtida uma correlação cofenética de 0,82 para uma matriz de Similaridade de Sørensen a partir de gêneros e de 0,79e 0,74 respectivamente para espécies e gêneros em matrizes de similaridade de Sørensen Relativa.

Em todas estas análises a flora arbórea de Santa Genebra, como esperado, apresentou maior similaridade com os levantamentos da região de Campinas (Ribeirão Cachoeira (RCch) e Fazenda Bela Vista em Pedreira (Pdrr)) (figura 2). A similaridade pode ser explicada, pela proximidade, pelo grau de perturbação aos quais as florestas foram submetidas e pela localização altitudinal entre 600 e 850 metros destas florestas, próximas ao limite entre as formações Montana e Alto Montana, definidas por Torres et al. (1997) entre 700 e $750 \mathrm{~m}$.

A altitude e a duração da estação seca foram sugeridas em outros estudos como fatores importantes que explicariam a distribuição de diferentes táxons nas florestas do interior do Estado de São Paulo (Torres et al.

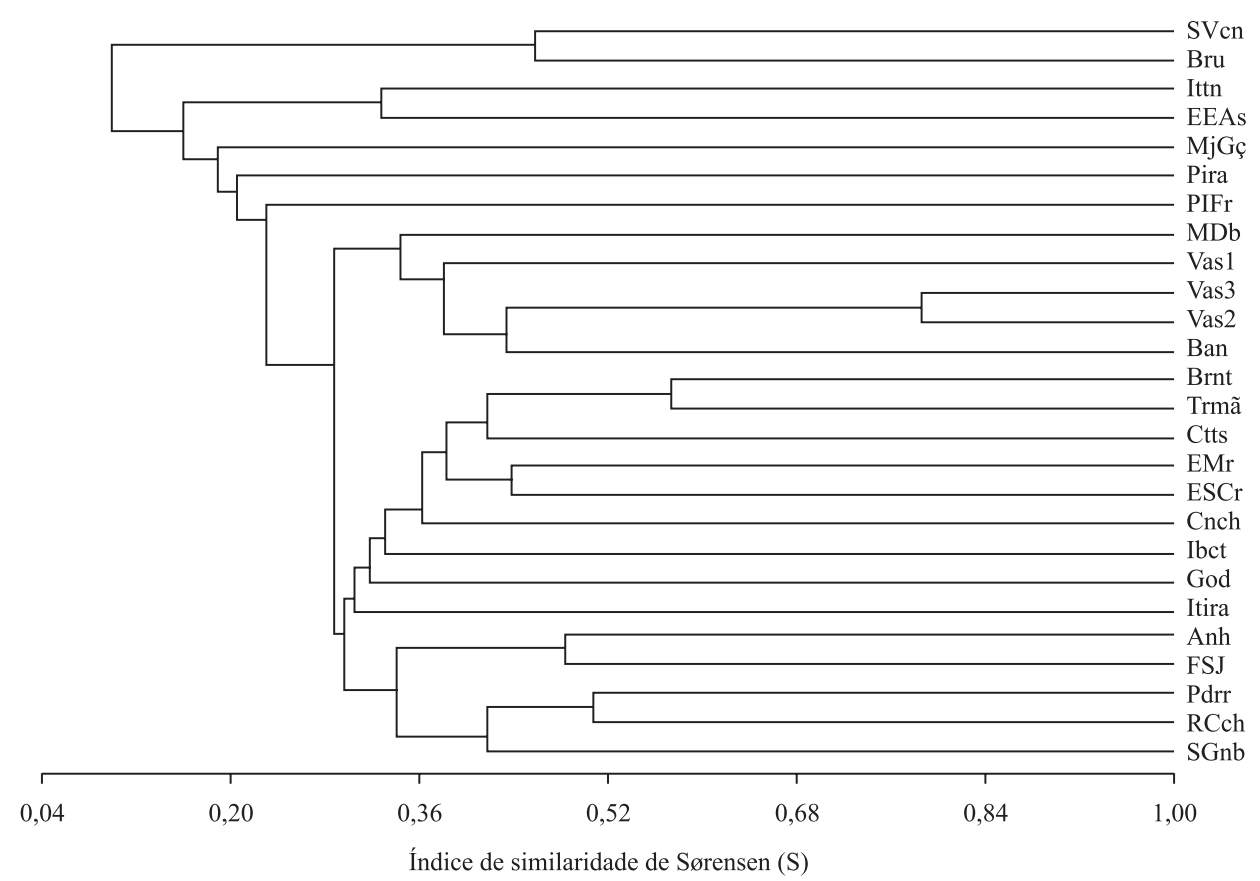

Figura 2. Índice de similaridade de Sørensen (S) para 26 levantamentos de espécies arbóreas em áreas de floresta nos Estados de São Paulo e Paraná agrupados por ligação por UPGMA. Ver tabela 1 para abreviaturas de áreas.

Figure 2. Sørensen's similarity index (S) for 26 tree species surveys in forest areas in São Paulo and Parana State grouped by UPGMA linkage. Study sites abbreviations in table 1 . 
1997, Oliveira Filho \& Fontes 2000, Santos \& Kinoshita 2003, Yamamoto et al. 2005) e também podem explicar os resultados obtidos. A floresta da Reserva Municipal de Santa Genebra e as florestas mais similares a ela encontram-se a uma altitude maior do que a da maioria dos levantamentos analisados.

O inventário florístico realizado na Reserva Municipal de Santa Genebra amostrou cinco espécies dos gêneros Trichilia (Meliaceae) e Machaerium, (Leguminosae) e quatro do gênero Zanthoxyllum (Rutaceae). Segundo os autores anteriormente citados, as famílias Meliaceae e Rutaceae e os gêneros Machaerium e Trichilia são característicos da formação floresta estacional submontana.

Dos gêneros presentes em ao menos seis localidades na matriz de dados ocorreram ao menos em dois dos três remanescentes na região de Campinas ( $\mathrm{SGnb}$, RCch e Pdrr): Ilex (Aquifoliaceae), Pseudobombax e Abutilon (Malvaceae), Luetzelburgia e Senna (Fabaceae), Calycorectes e Gomidesia (Myrtaceae), Seguieria (Phytollacaceae), Alseis, Guettarda e Psychotria (Rubiaceae), e Galipea (Rutaceae).

Das espécies da matriz de dados que ocorreram exclusivamente nesse grupo, ao menos em dois dos três locais, foram registradas no Planalto Atlântico no leste do estado com relativa freqüência: Myrciaria floribunda (Aragaki \& Mantovani 1993, Gandolfi et al. 1995, Aragaki 1997, Tomasulo \& Cordeiro 2000, Ogata \& Gomes 2006), Erythroxylum deciduum (Nastri et al. 1992, Gandolfi et al. 1995 Tomasulo \& Cordeiro 2000, Ogata \& Gomes 2006), e Eriotheca candolleana (K. Schum.) A. Robyns (Rodrigues et al. 1989, Grombone et al. 1989, Mantovani et al. 1990), além de Solanum granuloso-leprosum (Gandolfi et al. 1995), Eugenia excelsa (Aragaki \& Mantovani 1993, Grombone et al. 1989) e Eugenia ligustrina (Aragaki \& Mantovani 1993).

Por outro lado, todos os gêneros que ocorreram em pelo menos 13 dos 26 levantamentos (50\%), também estiveram presentes nestes remanescentes, mostrando que nesta região são encontrados todos os gêneros freqüentes nas florestas mesófilas semideciduais. Estes dados sugerem que, embora a floresta apresente áreas mais perturbadas, conserva trechos representativos da vegetação nativa de floresta mesófila estacional semidecidual característica de áreas mais elevadas do interior do estado.

\section{Referências bibliográficas}

APG (Angiosperm Phylogeny Group) II. 2003. An update of the Angiosperm Phylogeny Group classification for the orders and families of flowering plants: APG II. Botanical Journal of the Linnean Society 141:399-346.
ARAGAKI, S. 1997. Florística e estrutura de trecho remanescente de floresta no Planalto Paulistano (SP). Dissertação de mestrado, Universidade de São Paulo, São Paulo.

ARAGAKI, S. \& MANTOVANI, W. 1993. Estudos taxonômicos e estruturais de um trecho remanescente de floresta no Parque Municipal Alfredo Volpi (São Paulo, SP). In Anais do II Simpósio de Ecossistemas da Costa Brasileira (S. Watanabe, coord.). Academia de Ciências do Estado de São Paulo, São Paulo, p.68-80.

BAITELLO, J.B., PASTORE, J.A., DE AGUIAR, O.T., SÉRIO, F.C. \& DA SILVA. C.E.F. 1988. A vegetação arbórea do Parque Estadual do Morro do Diabo, Município de Teodoro Sampaio, Estado de São Paulo. Acta Botanica Brasilica 1:221-230.

BAKER, H.G. 1974. The evolution of weeds. Annual Review of Ecology and Systematics 5:1-24.

BAWA, K.S. \& MACDADE, L. 1994. The plant community: composition, dynamics, and life-history processes. In La Selva: ecology and natural history of a neotropical rainforest (L. MacDade, K.S. Bawa, H.A. Hespenheide \& G.S. Hartshorn, eds.). The University of Chicago Press, Chicago, p.65-72

BERNACCI, L.C. \& LEITÃO FILHO, H.F. 1996. Flora fanerogâmica da floresta da Fazenda São Vicente, Campinas, SP. Revista Brasileira de Botânica 19: 49-164.

BERTONI, J.E.A., MARTINS, F.R., MORAES, J.L. \& SHEPHERD, G.J. 1988. Composição florística e estrutura fitossociológica do Parque Estadual de Vassununga, Santa Rita do Passa Quatro - Gleba Praxedes. Boletim Técnico do Instituto Florestal de São Paulo 42:149-170.

BROKAW, N.V.L. 1985. Treefalls, regrowth, and community structure in tropical forests. In The ecology of natural disturbance and patch dynamics (S.T.A. Pickett \& P.S. White, eds.). Academic Press, San Diego, p.53-69.

BROKAW, N.V.L. \& SCHEINER, S.M. 1989. Species composition in gaps and sructure of a tropical forest. Ecology 70:538-541.

BUDOWSKI, G. 1965. Distribution of tropical American rain forest species in the light of successional processes. Turrialba 15:40-42.

CARVALHO, P.E.R. 1994. Espécies florestais brasileiras: recomendações silviculturais, potencialidades e uso da madeira. EMBRAPA, Brasília.

CAVASSAN, O., CESAR, O. \& MARTINS, F.R. 1984. Fitossociologia da vegetação arbórea da Reserva Estadual de Bauru, Estado de São Paulo. Revista Brasileira de Botânica 7:91-100.

CÉSAR, O. \& LEITÃO FILHO, H.F. 1990. Estudo florístico quantitativo de mata mesófila na Fazenda Barreiro Rico, município de Anhembi, SP. Revista Brasileira de Biologia 50:133-147.

COSTA, L.G.S. \& MANTOVANI, W. 1995. Flora arbustivoarbórea de trecho de mata mesófila semidecídua no sítio ecológico de Ibicatu, Piracicaba (SP). Hoehnea 22:47-59. 
CRONQUIST, A. 1981. An integrated system of classification of flowering plants. Columbia University Press, New York.

DA SILVA, L.A. \& SOARES, J.J. 2002. Análise sobre o estado sucessional de um fragmento florestal e sobre suas populações. Revista Árvore 26:229-236.

DENSLOW J.S. \& HARTSHORN, G.S. 1994. Tree-fall gap environments and forest dynamic processes. In La Selva: ecology and natural history of a neotropical rainforest (L. MacDade, K.S. Bawa, H.A. Hespenheide $\&$ G.S. Hartshorn, eds). The University of Chicago Press, Chicago, p.120-127.

DURIGAN, G., FRANCO, G.A.D.C., SAITO, M. \& BAITELLO, J.B. 2000. Estrutura e diversidade do componente arbóreo da floresta na Estação Ecológica dos Caetetus, Gália, SP. Revista Brasileira de Botânica 23:369-382

DURIGAN, G. \& LEITÃO FILHO, H.F. 1995. Florística e fitossociologia de matas ciliares do oeste paulista. Revista do Instituto Florestal 7:197-239.

FELICIANO, A.L.P., MARANGON, L.C., CAVALHEIRO, F., SANTOS, J.E., PIRES, J.S.R. 2000. Fitossociologia de um fragmento de floresta Estacional Semidecidual. Caso de estudo: Estação Ecológica de São Carlos, Município de Brotas, SP. In Anais do V Simpósio de Ecossistemas Brasileiros: conservação (S. Watanabe, coord.). Aciesp, São Paulo, v.3, p.300-308.

FONSECA, M.G., MARTINI, A.M.Z. \& SANTOS, F.A.M. 2004. Spatial structure of Aspidosperma polyneuron in two semideciduous forest in southeast Brazil. Journal of Vegetation Science 15:41-48.

GANDOLFI, S., LEITÃO FILHO, H.F. \& BEZERRA, C.L.F. 1995. Levantamento florístico e caráter sucessional das espécies arbustivo-arbóreas de uma floresta mesófila semidecídua no Município de Guarulhos, SP. Revista Brasileira de Biologia 55:753-767.

GIBBS, P.E. \& LEITÃO FILHO, H.F. 1978. Floristic composition of an area of gallery forest near Mogi Guaçu, state of São Paulo, S. E. Brazil. Revista Brasileira de Botânica 1:151-156.

GOMES, E.P.C., MANTOVANI, W. \& KAGEYAMA, P.Y. 2003. Mortality and recruitment of trees in a secondary montane rain forest in Southeastern Brazil. Brazilian Journal of Biology 63:47-60.

GRAHAM, A.W. \& HOPKINS, M.S. 1990. Soil seed banks of adjacent unlogged rainforest types in north Queensland. Australian Journal of Botany 38:261-268.

GROMBONE, M.T., BERNACCI, L.C, MEIRA NETO, J.A. A, TAMASHIRO, J.Y. \& LEITÃO FILHO, H.F. 1989. Estrutura fitossociológica da floresta semidecídua de altitude do Parque Municipal da Grota Funda (Atibaia Estado de São Paulo). Acta Botanica Brasilica 4:47-64.

HOPKINS, M.S., TRACEY, J.G. \& GRAHAM, A.W. 1990. The size and composition of soil seed banks in remnant patches of three structural rainforest in North Queensland. Australian Journal of Ecology 15:43-50.
HORA, C.R. \& SOARES, J.J. 2002. Estrutura fitossociológica da comunidade de lianas em uma floresta estacional semidecidual na Fazenda Canchim. São Carlos, SP. Revista Brasileira de Botânica 25:323-329.

IVANAUSKAS, N.M., RIBEIRO, R.R. \& NAVE, A.G. 2002. Fitossociologia de um remanescente de floresta estacional semidecidual em Itatinga-SP, para fins de restauração de áreas degradadas. Revista Árvore 26: 43-57.

KOEPPEN, W. 1948. Climatologia.Ediciones Fondo de Cultura Económica, Ciudad de Mexico.

KOTCHETKOFF-HENRIQUES, O. \& JOLY, C.A. 1994. Estudo florístico e fitossociológico em uma mata mesófila semidecídua da Serra do Itaquerí, Itirapina, Estado de São Paulo. Revista Brasileira de Biologia 54:477-487

KOVACH, W.L. 1999. MVSP - A multivariate statistical package for Windows. Kovach Computing Services, Pentraeth, Wales.

LAURENCE, W.F. \& COCHRANE, M.A. 2001. Synergistic effects in fragmented landscapes. Conservation Biology 15:1488-1535.

LEITÃO FILHO, H.F. 1995. A vegetação. In Ecologia e preservação de uma floresta tropical urbana - Reserva de Santa Genebra. Campinas (H.F. Leitão Filho \& L.P. Morellato, eds.). Editora da Unicamp, Campinas, p.19-29.

MANTOVANI, W., RODRIGUES, R.R., ROSSI, L., ROMANIUC-NETO, S., CATHARINO, E.L.M. \& CORDEIRO, I. 1990. A vegetação na Serra do Mar em Salesópolis, SP. In Anais do 2ำ Simpósio de Ecossistemas da Costa Sul e Sudeste Brasileira: Estrutura, Função e manejo (Academia de Ciência do Estado de São Paulo, org.). Academia de Ciência do Estado de São Paulo, Águas de Lindóia, p.348-384.

MARTINS, F.R. 1991. Estrutura de uma floresta mesófila. Editora da Universidade Estadual de Campinas, Campinas.

MCGARIGAL, K., CUSHMAN, S. \& STAFFORD, S. 2000. Multivariate statistics for wildlife and ecology research. Springer, New York.

MORELLATO, L.P.C. \& LEITÃO FILHO, H.F. 1996. Reproductive phenology of climbers in a Southeastern Brasilian Forest. Biotropica 28:180-191.

MÜLLER-DOMBOIS, D. \& ELLENBERG, H. 1974. Aims and methods of vegetation ecology. John Wiley, New York.

NASTRI, V.D.F., CATHARINO, E.L.M, ROSSI, L., BARBOSA, L.M., PIRRÉ, E., BEDINELLI, C., ASPERTI, L.M., DORTA, R.O. \& COSTA, M.P. 1992. Estudos fitossociológicos em uma área do Instituto de Botânica de São Paulo utilizados em programa de educação ambiental. Revista do Instituto Florestal 4:219-225

OGATA, H. \& GOMES, E.P.C. 2006. Estrutura e composição da vegetação no Parque CEMUCAM, Cotia, SP. Hoehnea 33:371-384. 
OLIVEIRA-FILHO, A.T. \& FONTES, M.A.L. 2000. Patterns of floristic differentiation among Atlantic forests in southeastern Brazil and the influence of climate. Biotropica 32:793-810.

OLIVEIRA-FILHO, A.T. \& RATTER, J.A. 1995. A study of the origin of central Brazilian forests by the analysis of plant species distribution patterns. Edinburg Journal of Botany 52:141-194.

PAGANO, S.N. \& LEITÃO FILHO, H.F. 1987. Composição florística do estrato arbóreo de mata mesófila semidecídua no município de Rio Claro (Estado de São Paulo). Revista Brasileira de Botânica 10:37-47.

PAGANO, S.N., LEITÃO FILHO, H.F. \& SHEPHERD, G.J. 1987. Estudo fitossociológico do estrato arbóreo em mata mesófila semidecídua, no município de Rio Claro (Estado de São Paulo). Revista Brasileira de Botânica 10:49-61.

PIZZO, M.A. 1997. Seed dispersal and predation in two population of Cabralea canjerana (Meliaceae) in the Atlantic forest of southeastern Brazil. Journal of Tropical Ecology 13:559-577.

PUTZ, F.E., BLATE, G.M., REDFORD, K.H., FIMBEL, R. \& ROBINSON, J. 2001. Tropical forest management and conservation of biodiversity: an overview. Conservation Biology 15:7-20.

RIZZINI, C.T. 1997. Tratado de fitogeografia do Brasil: aspectos ecológicos, sociológicos e florísticos. Âmbito Cultural Edições Ltda., Rio de Janeiro.

RODRIGUES, R.R., MORELLATO, L.P.C., JOLY, C. A. \& LEITÃO FILHO, H. F. 1989. Estudo florístico e fitossociológico em um gradiente altitudinal de mata estacional mesófila semidecídua na Serra do Japi, Jundiaí, SP. Revista Brasileira de Botânica 12:71-84

ROZZA, A. de F. \& RIBEIRO, C.A. 1990. Estudo florístico e fitossociológico de fragmento de mata ciliar do campus da ESALQ, Piracicaba, SP. In Anais do VIII Congresso da Sociedade Botânica de São Paulo (Sociedade Botânica de São Paulo, ed.). SBSP, Campinas, p.7-12

SALIS, S.M., SHEPHERD, G.J. \& JOLY, C.A. 1995. Floristic comparison of mesophytic semideciduous forests of the interior of state of São Paulo, Southeast Brazil. Vegetatio 119:155-164.

SANTOS, F.A.M., TAMASHIRO, J.Y., RODRIGUES, R. R. \& SHEPHERD, G.J. 1996. The dynamics of tree population in a semideciduous forest at Santa Genebra Reserve, Campinas, SE Brazil. In Annual combined ecologists/biologists as a problem solvers. Supplement to Bulletin of the Ecological Society of America. Rhode Island, USA. v.77, p.389.

SANTOS, K. \& KINOSHITA, L.S. 2003. Flora arbustivoarbórea do fragmento de floresta semidecidual do Ribeirão Cachoeira, Município de Campinas, SP. Acta Botanica Brasilica 17:325-341.

SCHINITZER, S.A. 2005. A mechanistic explanation patterns of liana abundance and distribution. The American Naturalist 166:262-276.
SETZER, J. 1966. Atlas climático e ecológico do Estado de São Paulo. Comissão Interestadual da Bacia ParanáUruguai e Centrais Elétricas do Estado de São Paulo, São Paulo.

SMITH, A.R., PRYER, K.M., SCHETTPELZ, E., KORALL, P., SCHEIDER, H. \& WOLF, P. 2006. A classification for extant ferns. Taxon 55:705-731.

SOARES-SILVA, L.H. \& BARROSO, G.M. 1992. Fitossociologia do estrato arbóreo da floresta na porção norte do Parque Estadual Mata dos Godoy, Londrina, PR, Brasil. In Anais do VIII Congresso da Sociedade Botânica de São Paulo (Sociedade Botânica de São Paulo, ed.). SBSP, Campinas, p.101-112.

STRANGHETTI, V. \& RANGA, N.T. 1998. Levantamento florístico das espécies vasculares da floresta estacional mesófila semidecídua da Estação Ecológica de Paulo de Faria - SP. Revista Brasileira de Botânica 21: 289-298.

TABARELLI, M. \& MANTOVANI, W. 1997. Colonização de clareiras naturais na floresta atlântica no Sudeste do Brasil. Revista Brasileira de Botânica 20:57-66.

TABARELLI, M., SILVA, J.M.C. \& GASCON, C. 2004. Forest fragmentation synergisms and the impoverishment of neotropical forests. Biodiversity and Conservation 13:1419-1425.

TOMASULO, P.L.B. \& CORDEIRO, I. 2000. Composição florística do Parque Municipal da Serra do Itapety, Mogi das Cruzes, SP. Boletim do Instituto de Botânica 14: 139-161

TONIATO, M.T.Z. \& de OLIVEIRA-FILHO, A.T. 2004. Variations in tree community composition and structure in a fragment of tropical semideciduous forest in southeastern Brazil related to different human disturbance histories. Forest Ecology and Management 198:319-339.

TORRES, R.B., MARTINS, F.R. \& GOUVEIA, L.S.K. 1997. Climate, soil, and tree flora relationship in forests in forests in the state of São Paulo, southeastern Brasil. Revista Brasileira de Botânica 20:41-49.

VELOSO, H.P., RANGEL FILHO, A.L.R. \& LIMA, J.C.A. 1991. Classificação da vegetação brasileira, adaptada a um sistema universal. IBGE, Rio de Janeiro.

VIEIRA, M.G.L., MORAES, J.L., BERTONI, J.E.A., MARTINS, F.R. \& ZANDARINI, M.A. 1989. Composição florística e estrutura fitossociológica da vegetação arbórea do Parque Estadual de Vassununga, Santa Rita do Passsa Quatro (SP). II - Gleba Capetinga Oeste. Revista do Instituto Florestal de São Paulo 1:135-159

WHITMORE, T.C. 1989. Canopy gaps and the two major groups of forest trees. Ecology 70:536-538.

YAMAMOTO, L.F., KINOSHITA, L. \& MARTINS, F.R. 2005. Florística dos componentes arbóreo e arbustivo de um trecho da Floresta Estacional Semidecídua Montana, município de Pedreira, estado de São Paulo. Revista Brasileira de Botânica 28:191-202. 